Journal of Jazz Studies, vol. 8, no. 1, pp. 4-32 (Spring 2012)

\title{
An Approach to Phrase Rhythm in Jazz ${ }^{1}$
}

\author{
Stefan Love
}

Phrase rhythm, the interaction of grouping and metrical structure, is an established area of inquiry in common-practice music. ${ }^{2}$ Numerous authors have also commented on phrasing in improvised jazz melody. Owens 1974 is typical:

A glance through [Charlie Parker's] solos reveals a great variety of phrase lengths, from two- or three-note groups lasting only one or two beats, to single sustained notes, to elaborate musical sentences of ten or twelve measures. Parker tended to construct his phrases to coincide with the phrase structure of the piece being performed. Thus, his solos in 32measure, "aaba* pieces generally show endings in the seventh or eighth measures of each section of each chorus. But deviations from this procedure abound, adding to the unpredictability and freshness of his performances. (14)

Though such observations are tantalizing, no author has pursued the topic in depth. ${ }^{3}$ Even rigorous definitions of the term "phrase" are rare. ${ }^{4}$ This aspect of jazz improvisation deserves fuller treatment.

In this paper, I present a method of phrase-rhythm analysis for improvised jazz melody. ${ }^{5}$ Here, "jazz" refers only to a subset of jazz, contemporaneously

\footnotetext{
${ }^{1}$ This paper is a refinement of the author's dissertation (Love 2011).

${ }^{2}$ Cone (1968), Lerdahl and Jackendoff (1983), Schachter (1980 and 1987), and Rothstein (1989) are foundational works on the topic. More recent work includes Braunschweig (2004/2005) and Temperley (2003 and 2008).

${ }^{3}$ Discussions of phrase rhythm in jazz solos also appear in Downs (2000/2001), Larson (1999), Larson et al (2009), Martin (1996, 112), and Waters (1996). Allen Forte $(1995,37)$ has examined phrase rhythm in jazz themes. Berliner (1994) discusses the performers' view of phrase rhythm.

${ }^{4}$ A rarity also noted in Downs $(2000 / 2001,42)$, one of the few works to offer a rigorous definition for "phrase."

${ }^{5}$ Strictly, solos need not be entirely improvised. The relationship between composition and improvisation is complex and the line between them is often blurry. For the purposes of this paper, however, it does not matter whether or not the solos are truly improvised [Larson (1998 \& 2005) takes a similar view]. For convenience, I will casually refer to "improvisation" as the process by which solos originate.
}

copyright by author $(9) \$ \bigoplus \begin{gathered}\text { Except where otherwise noted, this work is licensed under } \\ \text { http://creativecommons.org/licenses/by-nc-nd/3.0 }\end{gathered}$ 
referred to as "modern jazz," whose form and performance practice derive from bebop. Unlike most approaches to phrase rhythm, which focus on harmony and voice-leading, my approach is essentially metrical. It is based on several premises:

1. The metrical structure of a jazz performance, from the level of the quarternote to the chorus, is entirely fixed and determined in advance, and known to performers and listeners during a performance.

2. A metrical time-span is any unit of the metrical hierarchy, for example, a twobar hypermeasure.

3. Improvised melodies may be divided into segments, the smallest units of phrasing, which are defined chiefly through surface features like rests and relatively long notes.

4. A phrase is a segment, or set of segments, that corresponds with (that is, may be heard and understood with reference to) a metrical time-span.

5. Phrases form a hierarchy in parallel with the metrical hierarchy, but not necessarily aligned with it.

Explanation and expansion of these premises constitute the first part (and majority) of this paper. In the second part, I analyze a short passage from a solo by Bill Evans, illustrating the approach's flexibility when applied to an ambiguous example. Contradictory analyses of such passages are possible, as an analysis does not represent the only hearing, but rather a particular way of hearing the phrase rhythm.

My approach is not intended to replace existing approaches to jazz analysis. Rather, it is complementary: it focuses on an aspect of jazz that I believe has received too little attention. It can be combined with other approaches to present a more detailed picture of jazz melody.

\section{METER IN JAZZ}

Meter is a regular pattern of strong and weak beats, superimposed on the musical surface by the listener on the basis of informed expectation. ${ }^{6}$ These beats form a nested hierarchy of metrical levels, centered on the tactus, the "level of beats that is conducted and with which one most naturally coordinates foot-tapping and dance steps" (Lerdahl and Jackendoff 1983, 71). The quarternote is the most common tactus in jazz. Below the tactus are various divisions and subdivisions; above the tactus are half-notes, measures, and hypermeasures

\footnotetext{
${ }^{6}$ This definition draws on London (2004) and Lerdahl and Jackendoff (1983).
} 
(groups of multiple measures that seem to begin with a relatively strong beat; two- and four-bar hypermeasures are ubiquitous in jazz. $)^{7}$

Example 1 depicts the metrical structure of the first eight measures of Dewey Square, by Charlie Parker. The dots represent beats from the half-note to the eight-measure level. ${ }^{8}$ On every downbeat, there is a measure-level beat; every two measures, as on the downbeats of $\mathrm{mm} .1,3,5$, and 7 , there is a twomeasure-level beat, initiating a two-bar hypermeasure; every four measures, as on the downbeats of $\mathrm{mm} .1$ and 5, there is a four-measure-level beat, initiating a four-bar hypermeasure; finally, every eight measures, as on the downbeat of m. 1 (and m. 9, not shown), there is an eight-bar level downbeat, initiating an eight-bar hypermeasure (or "section"). ${ }^{9}$ A hypermeasure is not just any set of successive measures; rather, its beginning is marked with a downbeat heard as stronger than other downbeats, as established in the theme and by repetition throughout the performance. (Think of "trading fours": the musicians trade playing mm. 1-4, 5-8, 9-12, etc., rather than any arbitrary four-measure spans. These are hypermeasures.)

Example 1. Charlie Parker, "Dewey Square," theme, mm. 1-8, showing metrical structure at half-note level and above.

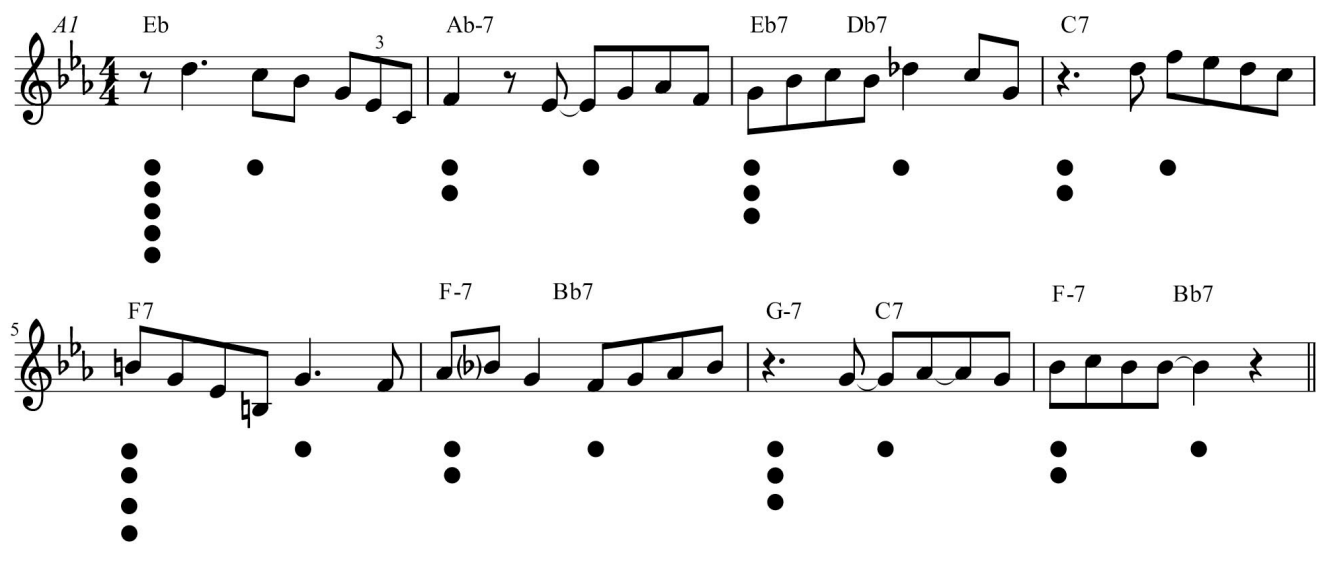

${ }^{7}$ The terms "hypermeter" and "hypermeasure" first appear in Cone $(1968,79)$, though I use the term in a sense deriving from Lerdahl and Jackendoff (1983).

${ }^{8}$ The dot notation originates in Lerdahl and Jackendoff (1983). I omit lower and higher levels of beats for visual clarity.

${ }^{9}$ In a thirty-two-measure theme, with four eight-measure sections, one might logically extend the metrical structure to the sixteen- and thirty-two-measure levels, although at those levels "meter" blurs into "form." 
A metrical time-span (my term) is a single unit of the metrical hierarchy, extending from a beat at a particular level to just before the next beat at that level. For my purposes, this includes single measures, along with two-, four-, and eight-bar hypermeasures. Example 2 shows the metrical time-spans in the first section of "Dewey Square." Different types of brackets show divisions between metrical time-spans at different levels: double-square brackets surround eight-bar hypermeasures; a single-square bracket divides this hypermeasure into two four-bar hypermeasures; angled brackets divide these into two-bar hypermeasures; and finally, vertical lines divide these into single measures.

Example 2. Brackets indicate the metrical time-spans of the first eight measures of "Dewey Square."

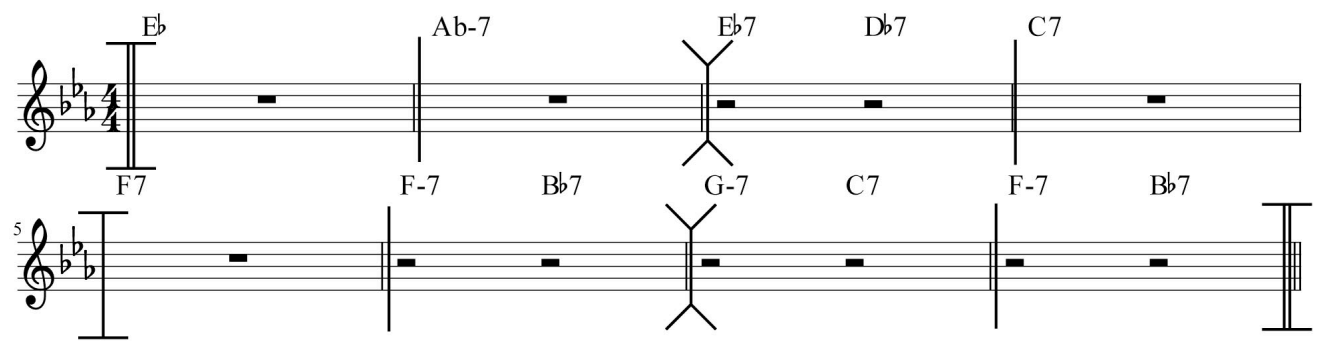

The solo choruses of a jazz performance strictly follow the metrical structure laid out by the theme: the solos that follow the theme of "Dewey Square" will strictly follow the metrical hierarchy shown in examples 1 and 2, even when the surface rhythm contradicts it. Indeed, strict adherence to the theme's metrical structure allows the ensemble to stay together through spontaneous passages of syncopation and polyrhythm, or extended drum solos. The experienced listener is aware of these conventions. First, the listener knows that within the jazz style, metrical structure is fixed in advance and will be repeated from chorus to chorus; and second, the listener knows many common metrical plans, such as thirty-two bar AABA. At any point during a performance, as soon as a listener determines a tune's metrical structure, the metrical structure of the remainder of the performance (at the chorus level and below) becomes a matter of near certainty. This applies to unfamiliar performances, and even performances of unfamiliar tunes, after the listener has heard one or two choruses. Thus, in this paper, I assume that the experienced listener has complete knowledge of the metrical structure, past, present, and 
future, from the tactus to the chorus-level. ${ }^{10}$ The meter presents a rigid background, against which the improvised melody is heard.

In this regard, jazz differs significantly from common-practice music. When they exist in common-practice music, a priori assumptions about metrical structure pertain to lower metrical levels only. For example, commonpractice listeners know that the meter at the measure-level is generally unchanging within a movement: a movement in 4/4 will stay in 4/4. ${ }^{11}$ They know certain generic conventions, for example that a movement marked "Minuet" will be in a moderate 3/4 time. But these assumptions pertain only to the measure-level, whereas the jazz listener can expect consistency through the chorus level (often thirty-two or more measures). In the common-practice, assumptions about levels above the single measure are far weaker: the listener might expect four-bar hypermeter at sectional beginnings, but would not be especially surprised if a piece departed from this convention. ${ }^{12} \mathrm{~A}$ jazz listener, on the other hand, would be quite surprised if Charlie Parker inserted a measure into a chorus, turning a four-bar hypermeasure into a five-bar hypermeasure-so surprised that the listener would probably assume it to be a mistake, unless it was repeated in every chorus.

More recent theoretical work emphasizes listeners' real-time determination and maintenance of meter in the act of listening (Hasty 1997; London 2004; Mirka 2009). Naturally, perceptual descriptions of meter are as valid for jazz as for any other style. However, I ignore these subtleties here. I believe the consistency and predictability of jazz meter permit me to take the metrical hierarchy for granted, as a background element against which the melody is heard. (I do acknowledge that even in this role, the meter is actively created by the listener.) I am not claiming that this is the best way to understand jazz meter, only that it is plausible, and can serve as the foundation of the approach below.

\section{DEFINING THE PHRASE}

In common-practice music, "phrases" are traditionally defined through harmony, and have been since the eighteenth century (Koch 1983).

\footnotetext{
${ }^{10}$ Exceptions can certainly be found, but they are outside the scope of this paper.

${ }^{11}$ Danuta Mirka (2009) scrutinizes this assumption, especially with respect to how contemporaneous listeners would have perceived meter in the Classical style; but her work strengthens my point by emphasizing the flexibility of common-practice meter.

${ }^{12}$ The notable exceptions to this rule are movements built on a theme-and-variations procedure, where the high-level metrical structure is often rigidly preserved; this is the very same procedure that underlies jazz performance.
} 
Undergraduates are taught that phrases end with a cadence. Scholars employ a more sophisticated version of the same approach: William Rothstein (1989, 5, 13) argues that the phrase contains "directed motion from one tonal entity to another," and that Schenkerian analysis is the best way to identify phrases. Carl Schachter (1980 and 1987) also uses Schenkerian analysis to define the phrase. Even approaches that are not strictly Schenkerian still approach the phrase harmonically (Caplin 2000; Cone 1968; Cooper and Meyer 1960). In common-practice music, these tonally defined phrases tend to be reinforced by rests, motives, relatively long notes, textural changes, and other surface features.

One can apply the same approach to jazz themes, identifying phrases through cadences and essential harmonic motions. ${ }^{13}$ This approach is less fruitful when applied to improvised jazz melody. The solo choruses of a jazz performance may modify the surface harmonies of the theme, but they preserve the deeper tonal structure-key areas and cadences. ${ }^{14}$ Therefore, if one identifies the "phrases" of an improvised melody through tonal motion alone, the results will be trivial: a phrase-rhythm analysis of four different solos on the same theme would find that all four employ nearly the same phrase structure. On the other hand, surface features, like rests, relatively long notes, or motives, often contradict the tonally defined phrases. To focus attention on the tonally defined phrase requires ignoring these surface features. Yet these features are varied and unpredictable, and seem equally worthy of attention.

This is not to discount the value of Schenkerian analysis of improvised jazz melody, which has been fruitfully performed by many theorists, notably Henry Martin (1996) and Steve Larson (1996 and 1998). (Indeed, middleground voice-leading figures into some of my phrase-rhythm analyses.) This method reveals how improvised melody expresses essential melodic or harmonic characteristics of the theme. Larson (1996, 152), for one, explicitly privileges voice-leading over surface features like rests: he claims that "the unity of linear progressions is not broken" by rests. Consequently, his analyses do not show rests or other non-tonal features of the melody, nor do other Schenkerian analyses. This leaves a gap in the research.

My approach attempts to fill this gap. I define melodic segments, the smallest units of the phrase structure, through the surface features neglected by other theorists. The approach is intentionally colloquial: when most jazz musicians speak of a "phrase," they are referring to a segment of melody

\footnotetext{
${ }^{13}$ Forte (1995) and Terefenko (2004) have analyzed many jazz standards this way.

${ }^{14}$ Strunk (1979) and Terefenko (2009) describe many modifications in detail.
} 
bordered by rests or relatively long notes, not a unified tonal motion (though the two, as in common-practice music, often coincide).

Some other authors share this focus on surface features. P.N. JohnsonLaird describes the jazz phrase as follows: "The boundary between [phrases] is demarcated by several cues. The main cue is rhythm. There is a longer than average interval from the onset of the last note in a phrase to the onset of the first note in the next phrase" $(2002,432)$. Johnson-Laird also mentions tonal stability as another sign of a phrase-ending (432-33).

Clive Downs (2000/2001, 42) offers a similar take on the jazz phrase, presenting a definition that is "precise enough that a computer program could be written to automatically detect the start and end of each phrase." According to Downs, a phrase:

- Contains no rests "of an eighth note or greater," except when

- The rest "has the effect of syncopation" or

- The rest divides a segment from another segment of three beats or less in duration, in which case the short segment is united with the larger segment into a single phrase. (42-43)

While I sympathize with Downs's goal of precision, I find his definition insufficient for broad application-although it matches my own findings in most cases. First of all, its focus on eighth-rests disregards musical context. In a passage in which the soloist uses primarily quarter notes or half notes, an eighth-rest would not seem particularly divisive. Second, Downs considers only rests, not inter-onset interval: the time between successive attacks (usually abbreviated IOI). ${ }^{15} \mathrm{~A}$ relatively long note, even if held until the next note begins, can be nearly as divisive as a rest of the same length, especially when reinforced by dynamics or contour. Finally, and most importantly, Downs does not explain whether or how phrases might form a hierarchy. Yet it seems clear that there are often multiple levels of phrase structure. Consider Example $3 .^{16} \mathrm{I}$ would identify four phrases at the lowest level, labeled A, B, C, and D. These group into the pairs $\mathrm{AB}$ and $\mathrm{CD}$ at a higher level. I would even say that $\mathrm{AB}$

\footnotetext{
${ }^{15}$ In this paper, I describe IOIs by rhythmic duration-half-note IOI, eighth-note IOI, etcin contrast with typical usage, in which IOI is a "clock time" measurement (e.g., 250 milliseconds).

${ }^{16}$ In Example 3 and most other examples (exceptions are exx. 5, 6, and 16A), I set one fourbar hypermeasure per line of music. Double-bars show sectional (eight-bar) divisions. Some of the transcribed excerpts are adapted from published sources, while others are by the author. A complete listing of relevant recordings and published transcriptions appears at the end of this paper. Published transcriptions were edited for accuracy and clarity, and re-notated at concert pitch when necessary.
} 
and CD together constitute a single phrase at a still higher level, given the parallelism between them. But Downs's definition only permits one level of phrase structure.

Example 3. Charlie Parker, "Cosmic Rays" (1952), mm. 1-8 (0:07).
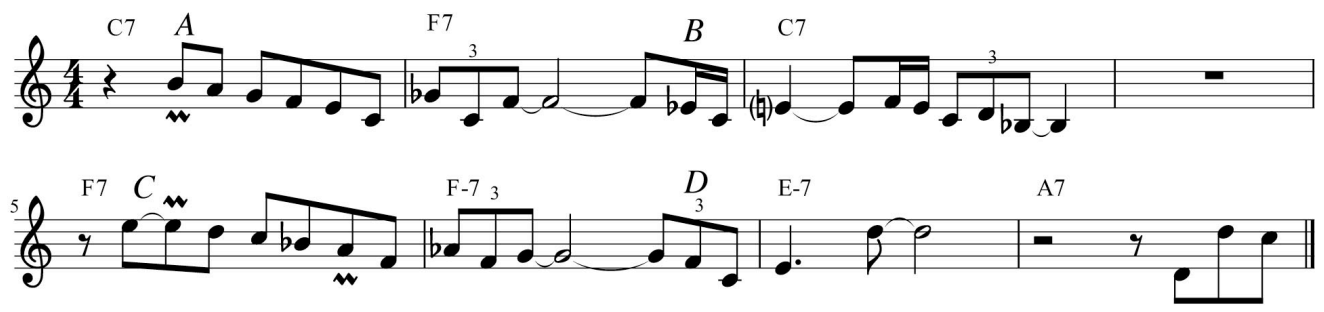

\section{SEGMENTATION—DISJUNCTIVE AND ASSOCIATIVE CRITERIA}

A segment is a continuous portion of melody that is set off from its surroundings by the events with which it begins and ends. The first step of a phrase-rhythm analysis is to divide a solo into segments. ${ }^{17}$ Together, all of the segments of a solo constitute the entire solo: there is no portion of the solo that does not belong to one segment or another, including all notes and rests. In this section, I list four criteria by which segments are identified. Borrowing a conceptual framework from Dora Hanninen (2001), I classify each criterion as disjunctive or associative: tending to divide events from one another, or tending to group events together. The disjunctive criteria are long IOIs and strong hypermetric beats; the associative criteria are melodic continuity and motive. I speculate that these criteria operate unconsciously in the mind of the experienced listener. They might also be viewed as a set of conscious strategies for shaping a listener's understanding of phrase structure.

A relatively long IOI divides segments from one another. This factor is significantly stronger than all other factors. IOI is contextual in its application: in a phrase constructed of half-notes, an IOI greater than a half-note would generally be necessary to suggest a segment boundary, while a quarter-note IOI might signal a boundary in an environment of eighth-notes. In Example 3 above, long IOIs, with and without rests, divide the first eight measures of

\footnotetext{
${ }^{17}$ Melodic segmentation has been extensively studied from a theoretical and cognitive point of view. Beyond the author's own intuition, this section draws on Lerdahl and Jackendoff (1983, esp. 43-52), Yeston (1974), and Hanninen (2001). Other relevant work includes Narmour (1990 and 1992), which address melodic perception in general; Temperley (2001), which develops a computational model of phrase analysis; and Spevak et al. (2002), which compares the output of several computational models of segmentation to the output of humans.
} 
"Cosmic Rays" into four segments. Rests strengthen the effect of a relatively long IOI, but are not strictly necessary.

Strong downbeats also help define segment boundaries. A strong beat encourages the placement of a grouping boundary at the nearest plausible point (typically a relatively long IOI, within a measure before or after the strong beat); the closer the plausible boundary is to the strong beat, and the stronger the beat, the greater the influence. ${ }^{18}$ There is a consequent tendency to hear segment divisions near eight-bar (sectional) downbeats, a weaker tendency to hear divisions near four-bar downbeats, and so forth.

In the absence of other factors, a strong beat is seldom sufficient to divide segments from one another. In other words, a steady stream of notes can overlap a strong beat without being heard as two segments. But strong beats can reinforce other factors. More frequently, strong beats help determine precisely where, within a long rest, to place a segment division: as near the strong beat as possible. In Example 4, IOI (reinforced by rests) divides the melody into three segments, labeled A, B, and C. (In this and future examples, letters designate segments.) Between segments $\mathrm{A}$ and $\mathrm{B}$, the criterion of strong beat suggests that the phrase division be placed at the last possible point within the IOI, as shown by the dotted line, in order to be as close as possible to the nearby four-bar downbeat (m. 101). This reflects the intuition that the rest in m. 100 "belongs" to segment A, and that the portion of segment B in m. 100 is an anacrusis to the next hypermeasure. Compare this with the long IOI between segments B and C, which overlaps a two-bar downbeat (103.1). The segment division falls directly on this beat. The half-rest before the division belongs to segment $\mathrm{B}$, the eighth-rest after, to $\mathrm{C}$.

Example 4. Divisions as near as possible to strong beats (Sonny Rollins, "Airegin," 4:08).

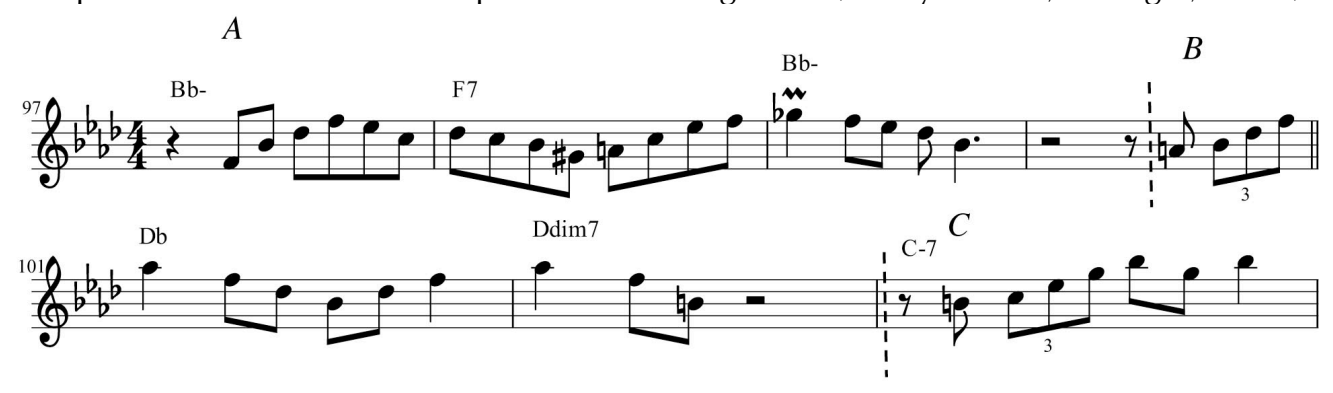

\footnotetext{
${ }^{18}$ This criterion is an inversion of Lerdahl and Jackendoff's Metrical Preference Rule (MPR) 2: "Weakly prefer a metrical structure in which the strongest beat in a group appears relatively early in the group" $(1983,76)$. Their rule suggests that, given a grouping structure, prefer a metrical structure that roughly coincides with it; my criterion suggests that, given a metrical structure, prefer a coincident grouping structure. In both cases, the intuition is that grouping and metrical structure ought to coincide when reasonable.
} 
Associative criteria encourage sets of events to be placed within the same segment or phrase (Hanninen 2001, 363). Associative criteria apply to all levels of phrase structure, not just the segment level: an associative feature like a motive often appears in two different segments, and would suggest that these segments belong together at a higher level. I formally introduce the phrase hierarchy in the next section; for now, it is enough to understand that segments are organized hierarchically into phrases, and that this process considers associative factors. The broadest associative criterion is melodic continuity, encompassing interval, contour, and middleground voice-leading. (This includes Johnson-Laird's criterion of tonal stability.) Motion in contextually small intervals and in a single direction encourages notes to be grouped together. Conversely, melodic discontinuity is a disjunctive criterion: changes in direction or contextually large intervals generally separate segments.

With respect to middleground voice-leading, linear progressions through triadic intervals encourage hearing a coherent segment or higher-level phrase; conversely, the endpoints of linear progressions suggest segment divisions. This particularly applies to higher levels of phrase structure. In Example 5, a single octave-progression unifies mm. 110-114, suggesting a high-level phrase, grouping three segments together. The phrase is roughly coextensive with a four-bar hypermeasure, so it is further reinforced by strong beats.

Example 5. An octave-progression suggests a single, high-level phrase (Sonny Rollins, "Moritat," 3:22). The second staff shows a reduction.

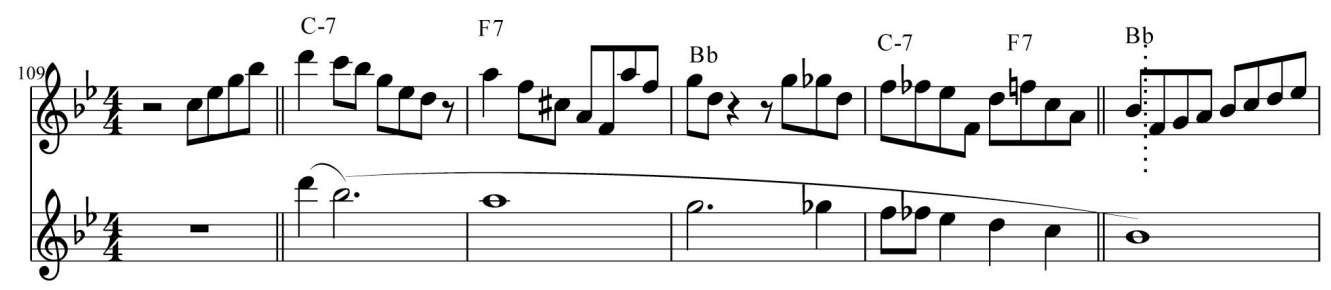

The repetition of a motive also suggests that events should be grouped together. Conversely, a change in motive suggests a grouping boundary, a disjunctive criterion. This factor is weak in isolation, but can augment other factors. In Example 6, the repetition of the ascending-third triplet motive from $\mathrm{mm}$. 21.3 to 24.2 encourages this passage to be heard as a phrase at some level (its location within a four-bar hypermeasure also supports this hearing). Three factors contribute to the boundary indicated before segment C: IOI, strong beat, and the abandonment of this motive. Considering IOI alone, segment $\mathrm{B}$ might plausibly be grouped with segment $\mathrm{C}$ : the IOI between them is relatively brief. The disappearance of the ascending-third motive after segment 
$\mathrm{B}$ contradicts this reading, and suggests a boundary. (An increase in dynamic level at segment $\mathrm{C}$, not shown in the transcription, reinforces the boundary.)

Example 6. A motive clarifies phrase structure (Bill Evans, "How Deep Is the Ocean?" $0: 40)$.

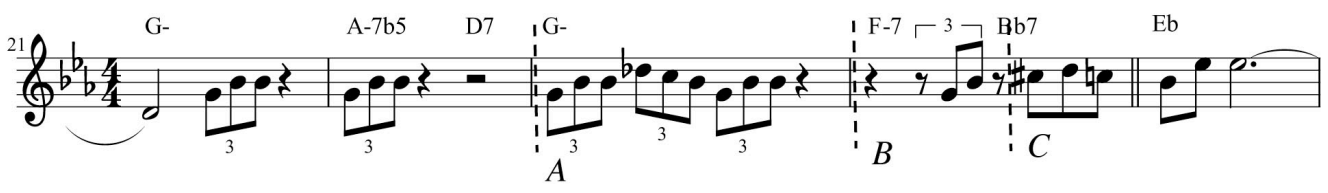

This list of four criteria is not exhaustive, although I believe it is sufficient in most cases. I invoke other criteria where necessary in the discussion that follows.

\section{THE PHRASE HIERARCHY}

Based only on the four criteria above, I could divide a melody into segments, observing how the criteria support or contradict one another to make the segmentation clear or obscure. But the lowest-level segments do not determine a particular phrase hierarchy. In this section, I explicitly associate the phrase hierarchy with the metrical hierarchy, as a "way of thinking" about jazz phrase structure (compare Hanninen 2001, 357). This outlook is implicit in the importance I grant to strong beats in the process of segmentation.

I introduce my approach through an analysis of a one-chorus Charlie Parker solo on "Ornithology," a tune based on the harmonic-metrical scheme of "How High the Moon." The tune divides into a 16/16 parallel-period structure, further divisible into four eight-bar sections. The phrase rhythm of much of this solo is quite transparent; I urge the reader to bear with me through the accompanying explanations, as they lay the groundwork for analyzing difficult examples. The purpose of this section is not to present insight into this solo, but to describe the analytical apparatus and its relationship to listeners' intuition.

Example 7 shows the first eight measures of Parker's solo. IOI suggests dividing this passage into two segments, labeled $\mathrm{A}$ and $\mathrm{B}$. There are three segment divisions: before segment $\mathrm{A}$, between the two segments, and after segment $\mathrm{B}$. The criterion of strong beat suggests that the division between $\mathrm{A}$ and $\mathrm{B}$ fall as close to $\mathrm{B}$ as possible, to be near the four-bar downbeat of m. 5 . Dotted lines show these divisions. 
Example 7. Charlie Parker, "Ornithology" (1946), mm. 1-8.
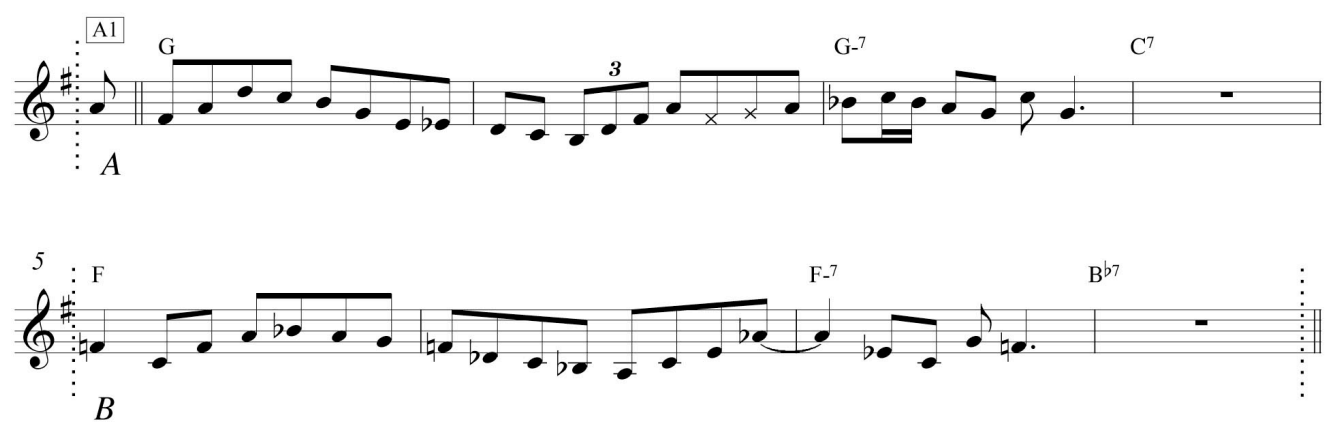

The next step of phrase-rhythm analysis is to associate each segment division with a division between metrical time-spans, as were introduced in Example 2 (reproduced as Example 8 below). This correspondence is largely a function of location, but can also incorporate intuitions about the relative significance of a melodic division (e.g., a deep melodic division, as would result from the coincidence of several segmentation factors, should be heard as corresponding with a deep metrical division, when plausible). In a finished analysis, I show segment divisions not with dotted lines, but with the very same brackets that appear in Example 8, modified to show any departures from the metrical structure.

Example 8. Metrical time-spans (copied from Example 2 above).

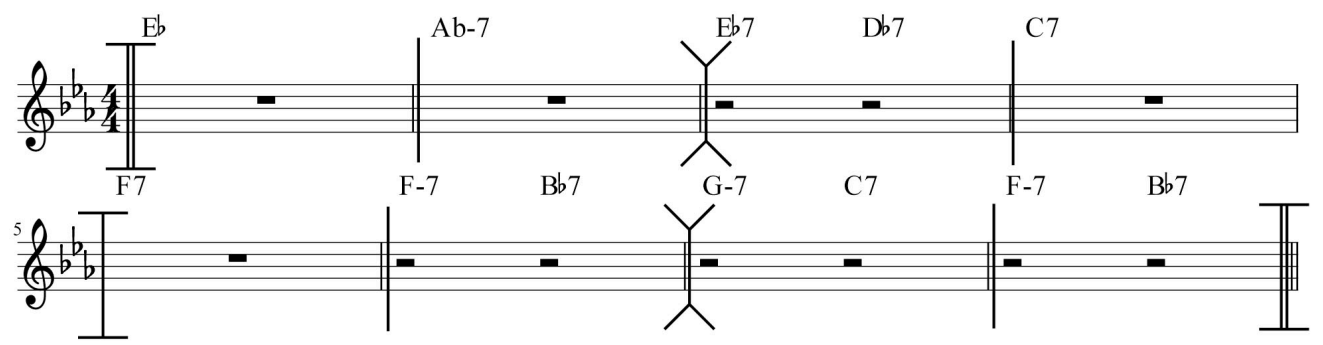

Example 9 replaces the dotted lines of Example 7 with brackets. The double-square brackets at the beginning and end show segment divisions corresponding with eight-bar metrical divisions. Notice that the first bracket is not symmetrical, like the equivalent bracket in $\mathrm{m}$. 8, but rather one-sided, pointing forward in musical time (to the right), and linked to the associated barline with dotted lines. This shows that segment A notes overlaps the downbeat of the metrical time-span to which the segment corresponds. The dotted lines show an anacrusis: the segment begins early, relative to the timespan. In m. 5, the single-square bracket shows segment division corresponding to the four-bar level of the meter. It is one-sided, like the bracket in $\mathrm{m}$. 0 , 
indicating overlap of the initial downbeat. (Even though such brackets are onesided, they mark not only the beginning of a segment but also the ending of the previous segment.)

Example 9. Analysis of "Ornithology," mm. 1-8.
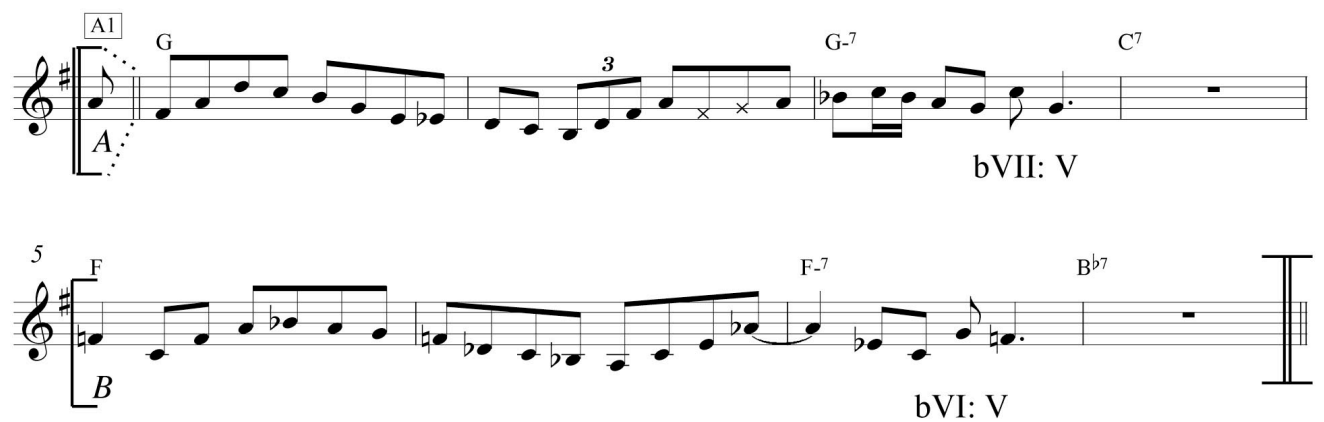

At this stage, I can identify phrases: segments or sets of segments that correspond with metrical time-spans. Segments A and B are both 4-phrases: they correspond with four-bar hypermeasures. This means more than that each phrase is four measures long. Rather, each is associated in the listener's mind with a particular four-bar hypermeasure of the tune, by virtue of the placement of its divisions and its melodic characteristics. Furthermore, segments $\mathrm{A}$ and $\mathrm{B}$ together form an 8-phrase: they correspond to the tune's first eight-bar hypermeasure.

These phrase labels say nothing about harmony. But it is worth noting that the melodic portions of both phrases end with the suggestion of locally dominant harmony. The result is an effect comparable to a half-cadence. I mark these moments accordingly: "bVII: V" means a melodic half-cadence in the key of bVII, while "bVI: V" means a half-cadence in the key of bVI. ("I" would show a full cadence, in the same fashion.) A melodic cadence occurs when a 4-phrase ends with melodic implication of local dominant or tonic harmony, coinciding with the theme's harmony. This does not require that there be a cadence in the theme at that point, only that there be the named harmony. The soloist can thus place melodic cadences even in places where the theme does not include them (and ignore cadences in the theme).

The phrase rhythm of this passage is highly consonant: the phrases fit neatly with their corresponding metrical time-spans, aside from the slight anacrusis to segment A. Example 10 depicts the phrase hierarchy of this passage. The top line shows measures, with the first measures of four-bar hypermeasures underlined. Below that are the successive levels of phrase 
structure: at the four-bar level are the two segments; below that, the eight-bar level includes a single 8-phrase, encompassing both segments.

Example 10. Phrase structure of "Ornithology," mm. 1-8.

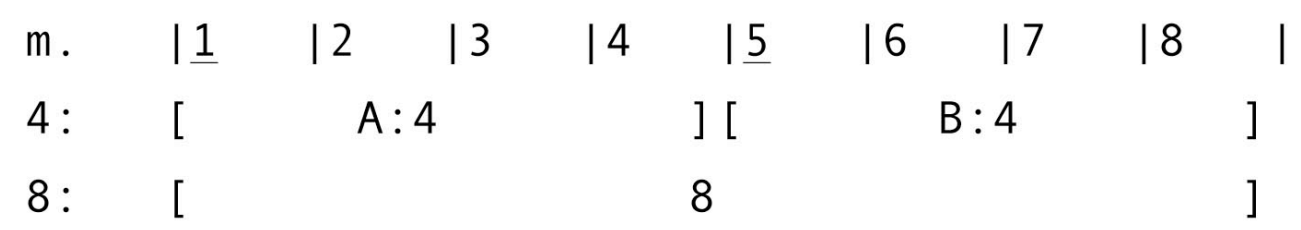

For now, I pass over the middle portion of Parker's solo to consider the final twelve measures (Example 11), including the final eight-bar section and the four measures preceding it. IOI suggests five segments, labeled $G$ through $K$. I have associated the division before $G$ with a four-bar division, shown with a square bracket. The division between $\mathrm{G}$ and $\mathrm{H}$ is more interesting. Strictly, it overlaps a metrical division at the one-measure level, between mm. 23 and 24 . However, I hear the beginning of segment $\mathrm{H}$ as an anticipation of the beginning of the next hypermeasure: it points forward, not back. The much greater strength of the upcoming eight-bar downbeat (m. 25.1) perceptually overrides the one-bar downbeat (m. 24.1). To put this another way: segment $\mathrm{H}$ initiates a new melodic gesture, marking a significant break from the previous segment; an eight-bar division better signifies this break. The double square bracket before segment $\mathrm{H}$ reflects this hearing, associating the beginning of $\mathrm{H}$ with the upcoming hypermetrical downbeat. As in segment $\mathrm{A}$, there is an anacrusis, though a bit longer in this case.

Example 11. Parker, "Ornithology," mm. 21-32.
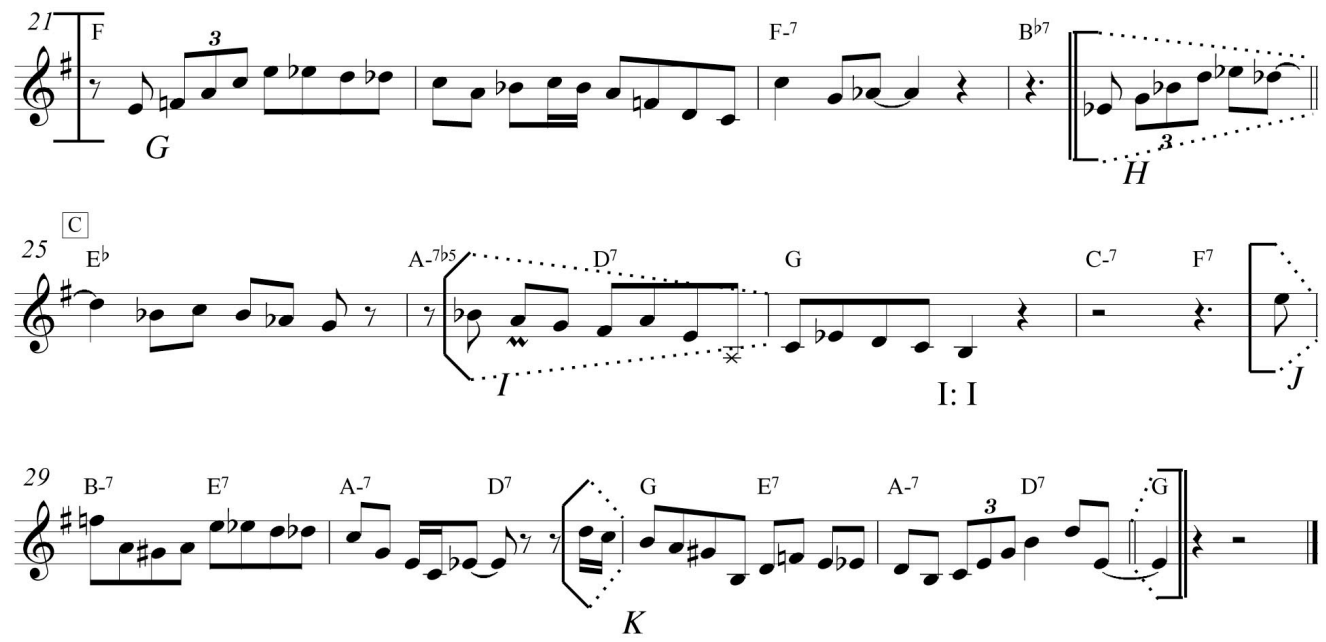
I hear the division between segments $\mathrm{H}$ and $\mathrm{I}$ in parallel fashion. Even though this division strictly overlaps a one-bar downbeat (m. 26), the beginning of segment $I$ is an anticipation of the upcoming two-bar downbeat, as captured by the one-sided angled bracket and anacrusis. Thus, segments $\mathrm{H}$ and I are offset from the meter; Parker "corrects" this imbalance with the long rest between I and J. Stability is also restored through a melodic cadence in $\mathrm{m}$. 27. The divisions before $\mathrm{J}$ and $\mathrm{K}$ are only slightly offset from their corresponding four- and two-bar downbeats. Segment K extends slightly into the next chorus, which is typical of a solo's final segment. The end of segment $\mathrm{K}$ introduces a new modification to the bracket notation: the backward-facing orientation. This shows that segment $\mathrm{K}$ overlaps the downbeat of the next hypermeasure. The portion of a segment that runs into the next hypermeasure is called an extension, the counterpart to the anacrusis.

Example 12 depicts the phrase structure of segments $\mathrm{H}, \mathrm{I}, \mathrm{J}$, and $\mathrm{K}(\mathrm{mm}$. 25-32). All four segments are 2-phrases. The pairs of segments HI and JK form 4-phrases at the next level, based on the locations of the four-bar downbeats, and the set of four segments form an 8-phrase, based on the locations of the eight-bar downbeats. On this view, segment H, a 2-phrase, falls in $\mathrm{mm}$. 24-25 but it corresponds to the two-bar hypermeasure in $\mathrm{mm}$. 2526. Segment I is a 2-phrase that actually spans three measures, $\mathrm{mm}$. 26-28. This paradox is only apparent, however; the "2" in 2-phrase refers not to the length of the phrase, but to the length of the corresponding metrical time-span (mm. 27-28). This approach is preferable to blindly categorizing segments $\mathrm{H}$ and I on the locations of their first and last notes, because the resulting analysis captures the intuition that $\mathrm{H}$ and $\mathrm{I}$, like $\mathrm{J}$ and $\mathrm{K}$, may be heard in relation to the two-bar hypermeasures of the theme: $\mathrm{H}$ and $\mathrm{I}$ are distortions of a norm, more neatly represented by $\mathrm{J}$ and $\mathrm{K}$; they do not follow a different phrase structure altogether.

Example 12. Phrase structure of "Ornithology," mm. 25-32.

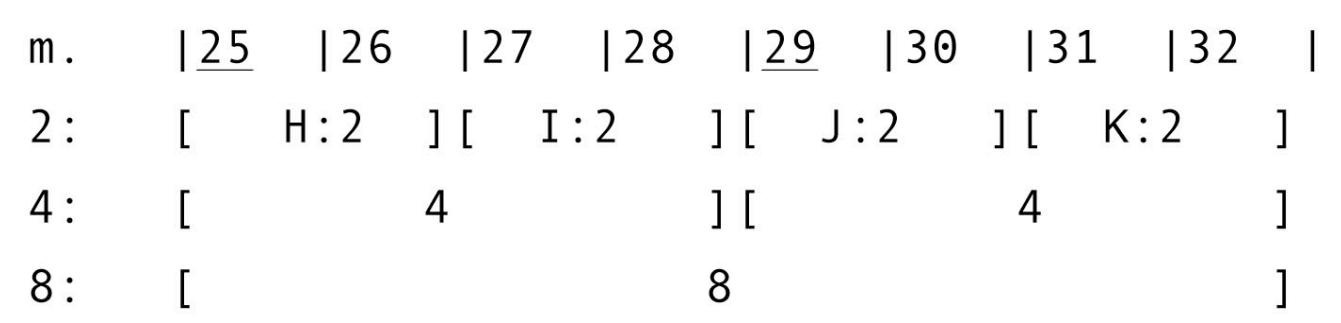

A phrase may have any of four accentual orientations. The notes of a phrase may overlap the downbeat of its metrical time-span (as shown with a 
forward-facing one-sided bracket), or they may not; the end of the phrase may overlap the downbeat of the next time-span at that level (as shown with a backward-facing one-sided bracket), or it may not; there are four resulting combinations. Taken together, the brackets around a phrase indicate its orientation. I label the types as follows:

- Un-accented. Neither the beginning nor the end of the phrase overlaps a relevant downbeat: the phrase begins after the downbeat of the time-span to which it corresponds and ends before the next downbeat at that level. (Example 11: segment G, a 4-phrase.)

- Beginning-accented. The phrase's notes overlap the downbeat of its timespan, but do not overlap the next downbeat at that level. This often includes, but does not require, an anacrusis. (Example 9: segment A, a 4-phrase.)

- End-accented. The phrase's notes do not overlap the corresponding metrical time-span's initial downbeat, but they overlap the downbeat of the next timespan at that level. This requires an extension. We have not yet seen any true end-accented phrases, only double-accented phrases (see below), which overlap a downbeat at their beginning and end.

- Double-accented. The phrase overlaps its initial downbeat and the downbeat of the next time-span at that level. (Example 11: segment K, a 2-phrase, overlaps two successive two-bar downbeats $(31.1,33.1)$; segments $\mathrm{J}$ and $\mathrm{K}$, together, are a double-accented 4-phrase that overlaps two successive four-bar downbeats $(29.1,33.1)$. The double-accented final phrase of the solo elevates tension leading into the next soloist.)

Accentual orientation is another means by which soloists introduce variety into their phrase rhythm. Beginning- and un-accented phrases are the most consonant; double- and end-accented phrases are more dissonant. The former types might be said to follow a norm, from which the latter types deviate.

The accentual orientation of the normative phrase is a point of contention in theories of common-practice music. ${ }^{19} \mathrm{I}$ have argued that meter in jazz has complete independence from phrase structure, and is dictated only by the theme. I also treat metrical time-spans, which begin with strong beats, as default units of phrasing. It is thus not surprising that $I$ favor the norm of beginning-accentuation. This is not to say that beginning-accented phrases are the most common, statistically (although I believe they are). I am instead arguing that beginning- and un-accented phrases better accord with the meter

\footnotetext{
${ }^{19}$ On the side of normative beginning-accentuation: Lerdahl and Jackendoff $(1983,76)$, Rothstein (1989, 28-29), and Schachter (1980, 205); end-accentuation: Cooper and Meyer $(1960,61)$ and Komar $(1971,151,155)$; no default accentuation: Cone (1968, 27), Lester $(1986,177)$.
} 
than the other types. I consider the metrical structure itself to be beginningaccented, because each metrical time-span extends from a given beat to just before the next beat at that level. ${ }^{20}$ End-accentuation is more dissonant than beginning-accentuation, and extensions are more dissonant than anacruses, because they contradict the metrical structure more severely.

Parker's phrase structure departs more radically from the meter in the middle portion of his solo (mm. 9-20, shown in Example 13 with a preliminary analysis). IOI suggests dividing this passage into segments $\mathrm{C}, \mathrm{D}$, $\mathrm{E}$, and $\mathrm{F} .{ }^{21}$ The division before $\mathrm{C}$ aligns with an eight-bar metrical division (also shown at the end of Example 9). The divisions between D and E (m. 15), and $\mathrm{E}$ and $\mathrm{F}$ (m. 18), clearly correspond with two-bar divisions.

The division between $\mathrm{C}$ and $\mathrm{D}(\mathrm{mm} .13-14)$ is harder to associate with a particular metrical division: does it correspond with the four-bar division between $\mathrm{mm} .12$ and 13, or the one-bar division between $\mathrm{mm} .13$ and 14? In other words, is segment $\mathrm{C}$ a 4-phrase, corresponding to $\mathrm{mm}$. 9-12, that slightly stretches its final boundary (like segment $\mathrm{K}$ in Example 11), or does it actually "break" that final boundary and include m. 13 as well?

Its location alone cannot answer this question-segments can be offset slightly from corresponding metrical divisions. At first (Example 13), one might interpret segment $\mathrm{C}$ as an end-accented 4-phrase with a slight extension (the backwards-facing final bracket is akin to that in Example 11 above). However, in previous examples of 4-phrases, a deep metrical division has been matched by a correspondingly deep melodic division: a square bracket, denoting a division at the four-bar level, has separated two distinct melodic gestures. Thus, this analysis implies hearing a sharp break after segment $\mathrm{C}$, and segment $\mathrm{D}$ as the beginning of something new. This denies the melodic connection between the end of $\mathrm{C}$ and the beginning of $\mathrm{D}$ : the A-F\# third. The repetition of this gesture leads me to hear the end of segment $\mathrm{C}$ not as the close of a gesture, but rather as the beginning of something new, which segment $\mathrm{D}$ continues. Therefore, a four-bar division after segment $\mathrm{C}$ would suggest far greater closure than I hear.

\footnotetext{
${ }^{20}$ The impression of beginning-accented phrases as normative is further reinforced by the phrase structures of most jazz themes, which tend to employ beginning-accented phrases.

${ }^{21}$ The division between $\mathrm{C}$ and $\mathrm{D}$ is debatable, established by IOI and strong beat but weakened by voice-leading; I retain it for didactic purposes.
} 
Example 13. Parker, "Ornithology," mm. 9-20. Preliminary analysis.
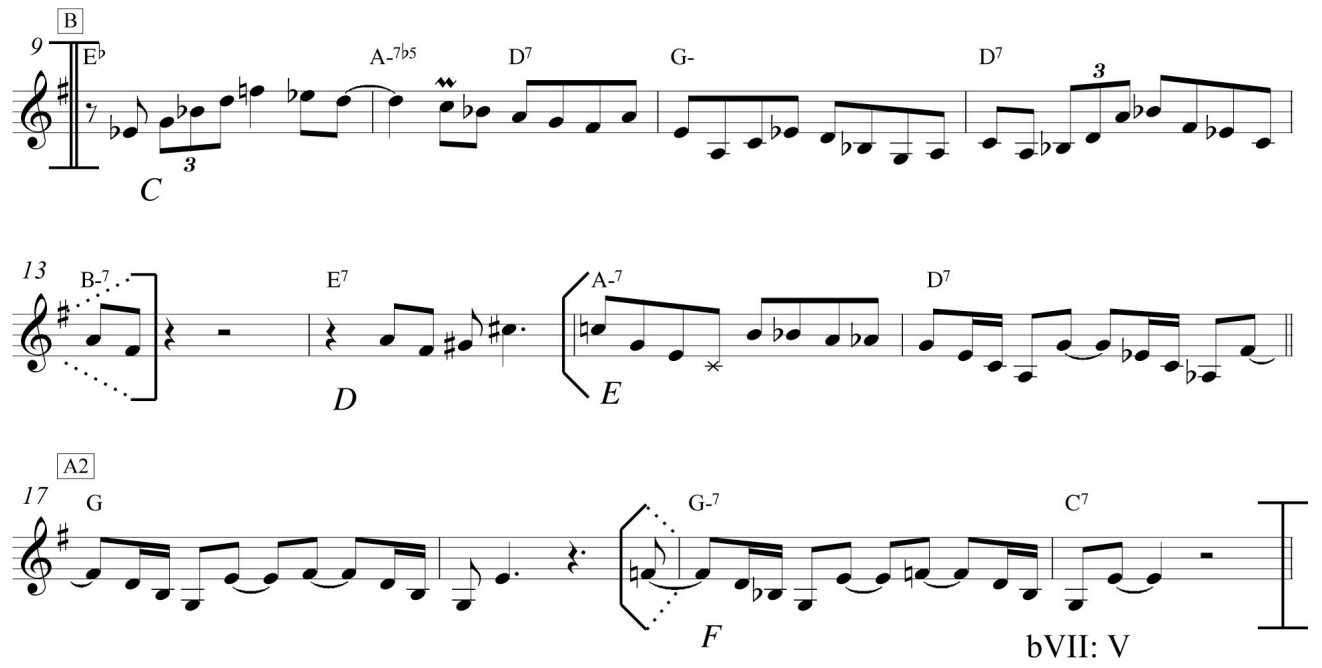

Example 14 presents my preferred analysis, which associates the end of $\mathrm{C}$ with the one-bar division between $\mathrm{mm} .13$ and 14. This suggests hearing segment $\mathrm{C}$ as truly including $\mathrm{m}$. 13-as blurring the four-bar metrical boundary, rather than merely stretching it. The vertical line between $\mathrm{C}$ and $\mathrm{D}$ denotes division at the one-measure level, as in Example 8 above. The melodic continuity between segments $\mathrm{C}$ and $\mathrm{D}$ matches the shallowness of this metrical division. I reiterate: this is not because segment $\mathrm{C}$ overlaps $\mathrm{m}$. 13 by a beat, but rather because its ending sounds like the beginning of a new melodic gesture, that continues into segment $\mathrm{D}$ and beyond. It would thus be misleading to place a deep phrase division here.

This analysis has significant consequences for the phrase structure: segment $\mathrm{C}$ is no longer a "phrase," by the definition given above: it does not correspond to a metrical time-span, but rather to two: the four-bar hypermeasure in $\mathrm{mm} .9-12$ and the single measure 13. It is therefore a combined phrase, a segment corresponding to multiple metrical time-spans. Specifically, it is a " $4+1$ " combined phrase. Heard this way, it overlaps an important metrical division, the four bar division between mm. 9-12 and 1316, without articulating an equivalently "deep" melodic division. Therefore, it suppresses this metrical division. A suppressed division is shown with a dotted bracket. Compared to example 13, the analysis in example 14 better captures the unity of $\mathrm{C}$ and $\mathrm{D}$ and the general lack of closure in this portion of the solo. 
Example 14. Preferred analysis of "Ornithology," mm. 9-20.
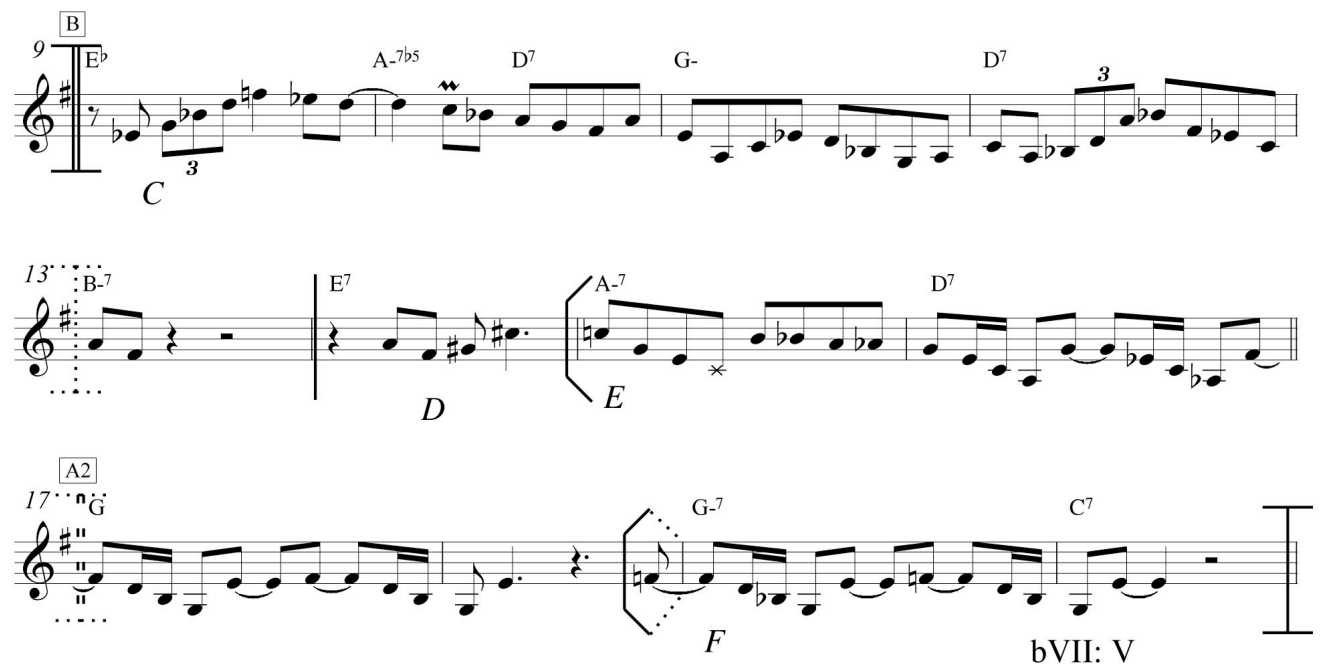

Segment $\mathrm{E}$ is also irregular. Like segment $\mathrm{C}$, it corresponds not to one metrical time-span, but to two: the two-bar hypermeasures in mm. 15-16 and 17-18. It is a $2+2$ combined phrase. (Even though it extends across four measures, it is not a 4-phrase: those four measures are not a four-bar hypermeasure, and the placement of this segment actually conflicts with the four-bar hypermeter of the tune.) This phrase suppresses the eight-bar division between mm. 16 and 17, which marks the midpoint of the chorus. Parker's use of motive intensifies this suppression: he introduces a descending seventhchord motive in m. 16 and continues it through m. 17. Segment F is a 2phrase, balancing the second half of segment $\mathrm{E}$.

Example 15 shows the phrase structure of this passage. Notice that there is no four- or eight-bar level, because none of the segments or sets of segments within this passage correspond with four- or eight-bar hypermeasures. This represents highly dissonant phrase rhythm, far more dissonant than the anacruses of segments $\mathrm{H}$ and $\mathrm{I}$. The dissonance is resolved between segments $\mathrm{F}$ and $\mathrm{G}$ (Example 11): the half-cadence in m. 20 lays the groundwork for the closer alignment of segment $G$ with the meter. Parker's solo thus achieves a peak of phrase-rhythm dissonance in the middle, followed by a gradual decline towards the end of the solo. It is also noteworthy that segment $\mathrm{E}$ obscures the theme's most important formal boundary, the division between the 16-measure halves of the chorus. The large-scale harmonic structure of the theme is obscured. Blurring formal boundaries through combined phrases is common in jazz, and has no equivalent in common-practice music. (The closest equivalent is phrase overlap, discussed below.) 
Example 15. Phrase structure of "Ornithology," mm. 9-20.

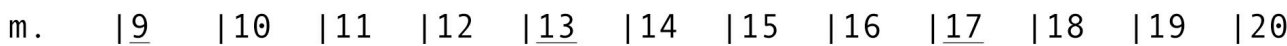

$$
\begin{aligned}
& \text { 1: [ C: } 4+1 \quad \text { ] }[D: 1] \\
& \text { 2: [ } 4+2 \text { ] [ E: } 2+2 \quad \text { ] } F: 2 \text { ] }
\end{aligned}
$$

This solo has introduced most of the concepts underlying my approach: the phrase hierarchy, including 1-phrases, 2-phrases, 4-phrases, 8-phrases, and combined phrases; the four accentual orientations of the phrase; and phrase rhythm dissonance, brought about by anacrusis, extension, or phrase combination. One more concept requires mention: phrase overlap. This phenomenon is familiar from common-practice music. In a phrase overlap, a single pivot note on or near a hypermetrical downbeat serves both to end a phrase and begin the next phrase. The pivot note properly belongs to both phrases: neither phrase would be complete without it.

Example 16 shows a typical instance. The $\mathrm{A}$ in $\mathrm{m}$. 89, on a four-bar downbeat, is a perfect pivot note: it stands out for being longer than the notes around it, as a point of harmonic resolution, and because of the different rhythms before and after. The first 4-phrase ends with this note and the second 4-phrase begins with it. Note the special bracket that indicates its status. Example 16B shows the resulting phrase hierarchy: the phrase rhythm is still quite consonant, since the pivot note places a phrase division at an important metrical division (the division is shown with "O", for "overlap"). As in common-practice music, phrase overlap preserves forward momentum while articulating two distinct gestures. This phenomenon is distinct from the combined phrase, in which there is no single point at which one phrase ends and the next begins. Contrast the phrase overlap in Example 16 with segment $\mathrm{E}$ in Example 14above, which crosses a hypermetrical boundary but is indivisible.

Example 16A. Bill Evans, "Solar," mm. 85-93 (1:59).

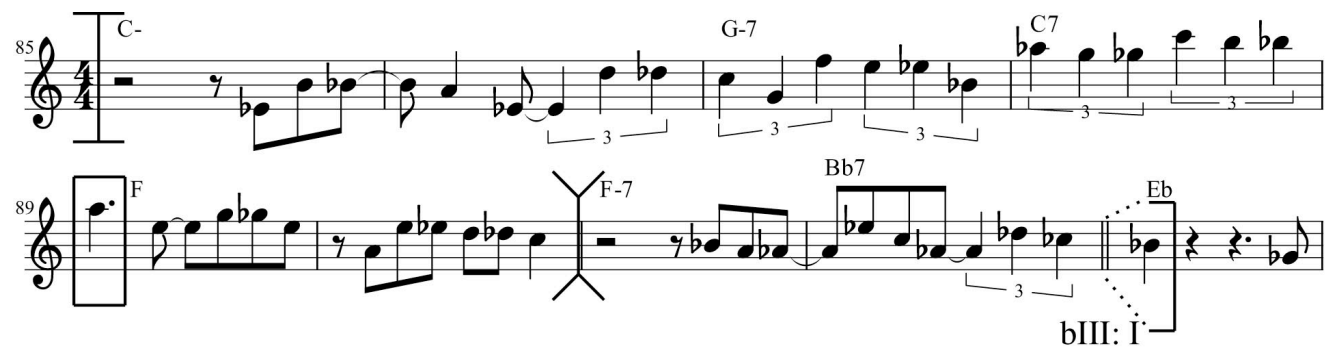


Example 16B. Diagram of above.

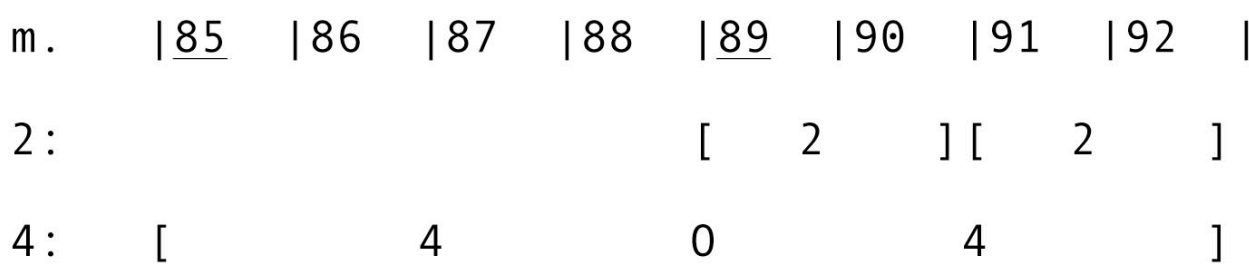

Rothstein $(1989,48)$ writes the following about overlap in commonpractice music: "A phrase overlap is most likely to occur when the first of two phrases ends either at (or just after) a hypermetrical downbeat." The same is true in jazz: as I define it, a pivot note almost always falls on a hypermetrical downbeat. The metrical accent on the pivot note encourages the hearing of a phrase boundary. A pivot note also stands out from the surrounding melody in some other way, most often through duration or contour. (Pivot notes at melodic peaks and valleys are especially common.)

Example 17 summarizes the notations used thus far, along with some others that have not yet been used. Familiarity with these symbols will greatly aid comprehension of the next section.

Example 16. Summary of phrase-rhythm notations.

On the beat

Beg.-acc.

Anacrusis

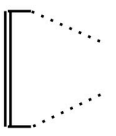

4-bar div.

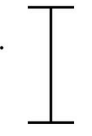

2-bar div.
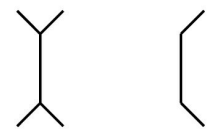

1-bar div.
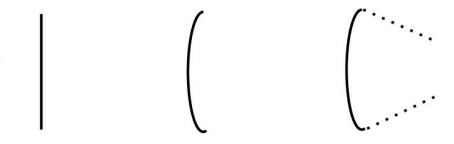
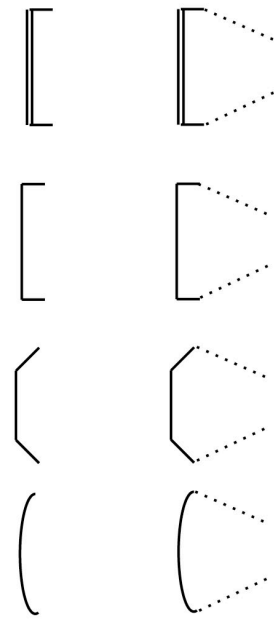

Extension (end-acc.) Overlap
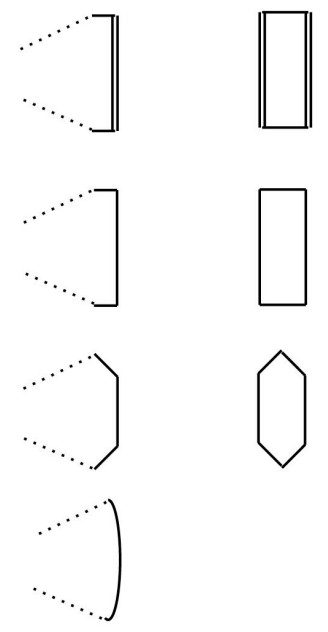

Half

Full

Melodic cadence (x is local key)

$\mathrm{x}$ : V

x: I 


\section{AN AMBIGUOUS EXAMPLE}

Parker's solo was ideal to introduce my approach but less suited to demonstrating its versatility. In this section, I present a final example to demonstrate how phrase-rhythm analysis can illustrate two different hearings of an ambiguous passage.

In Example 18, Bill Evans's phrase rhythm creates deep dissonance between melodic and metrical parallelism. This points to at least two plausible, contradictory phrase-rhythm analyses, each suggesting a radically different hearing. The example is from Evans's solo on the tune "Withcraft," and includes the bridge and the four measures prior.

Example 17. A passage with (at least) two possible analyses (Bill Evans, "Witchcraft," mm. 61-73 (2:10)).
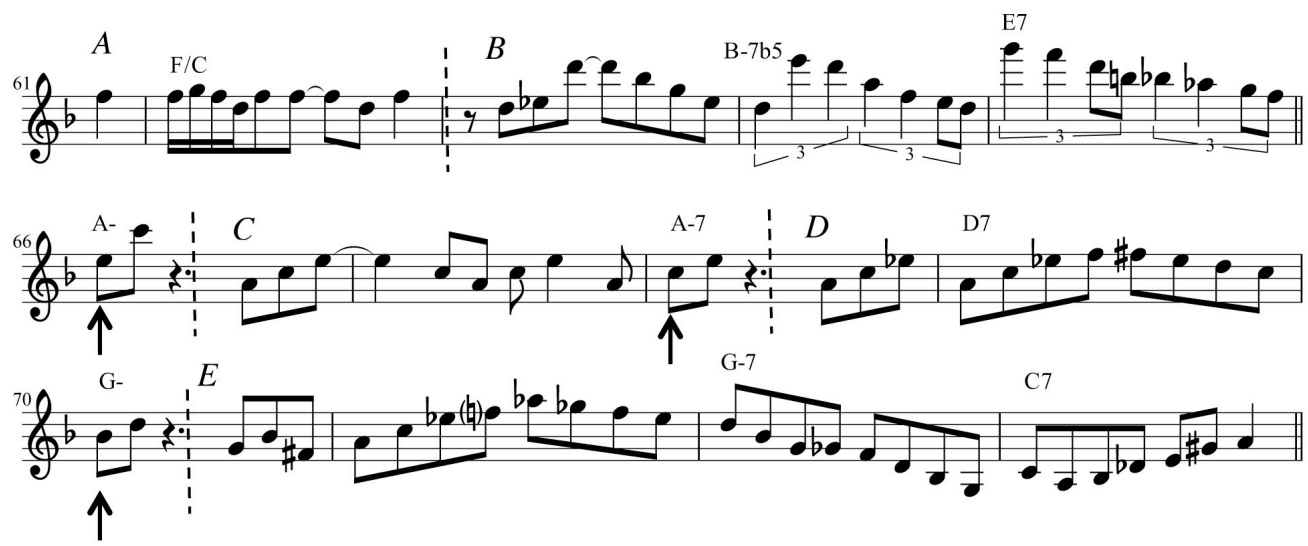

The ambiguity stems from three "rhyming" phrase endings, marked with arrows. Rhyme is often casually invoked in discussions of music, but I use the term in a very specific way. Two segments rhyme when their notes begin or end at the same point within a metrical time-span. Two segments whose notes begin at the same relative metrical location have beginning-rhyme; two segments whose notes end at the same relative metrical location have endrhyme. End-rhyme is generally more conspicuous than beginning-rhyme, as in poetic verse. Due to the intuition that parallel structures should be grouped together, rhyming phrases or segments should be grouped together at a higher level, when reasonable. Here, Evans employs end-rhyme at two-measure intervals.

Both analyses (Example 18) begin in the same way: segment $A$ opens the passage with a 1 -phrase; segment $B$ is a $1+2$ combined phrase, answering the 
opening 1-phrase and then suppressing the two-bar downbeat in the middle of the line (64.1), filling the rest of the four-bar hypermeasure. At this point, the analyses differ, with the differences revolving around the treatment of the rhyming endings. In analysis 1 , each of these terminates an end-accented phrase: segment B completes an end-accented 4-phrase; $\mathrm{C}$ and $\mathrm{D}$ are endaccented 2-phrases, together forming a 4-phrase. Segment $\mathrm{E}$ stands alone as an un-accented 4-phrase. The analysis receives its greatest support from the parallelism between segments $\mathrm{C}$ and $\mathrm{D}$, highly suggestive of parallel 2-phrases, part of a single larger unit (a 4-phrase). Furthermore, Evans's abandonment of the end-rhyme after segment $\mathrm{D}$ supports hearing a deep division after this segment, reinforcing the 4-phrase division in $\mathrm{m}$. 70. This interpretation suggests that the only real dissonance in the passage comes from the endaccentuation. However, it also suggests hearing a deep division after segment $B$, which separates the first appearance of the rhyme from subsequent appearances. I find it difficult to hear the end of segment B as conclusive; to me it sounds like the beginning of something new. But the 8-phrase ending here suggests firm closure.

$\begin{array}{llllll}\text { Example } 18 . & \text { Two possible analyses of example } 17 .\end{array}$

Analysis 1
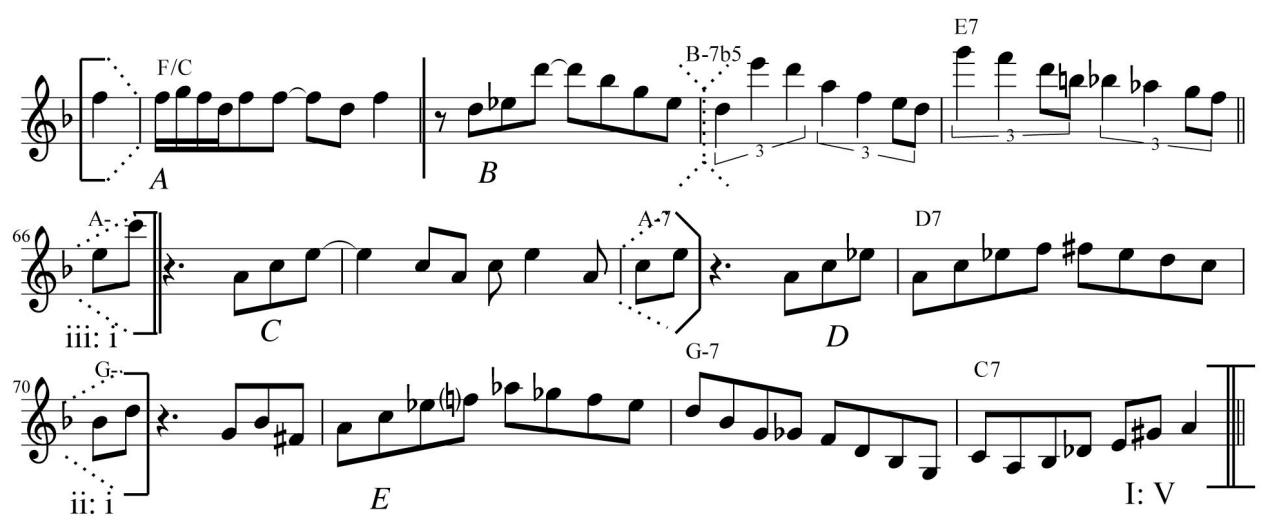

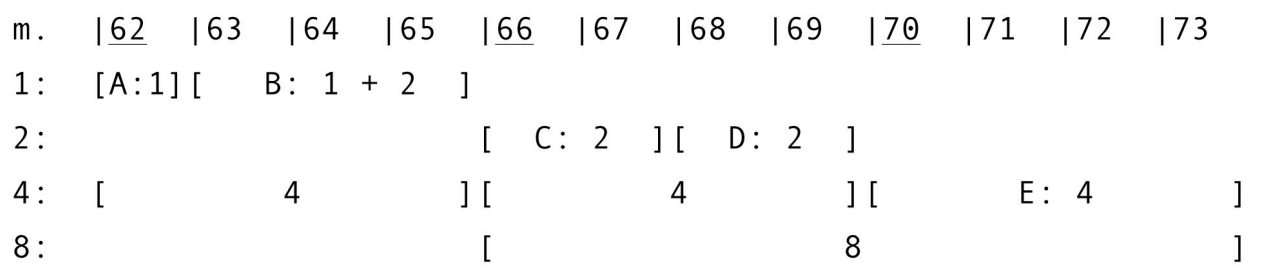


Analysis 2
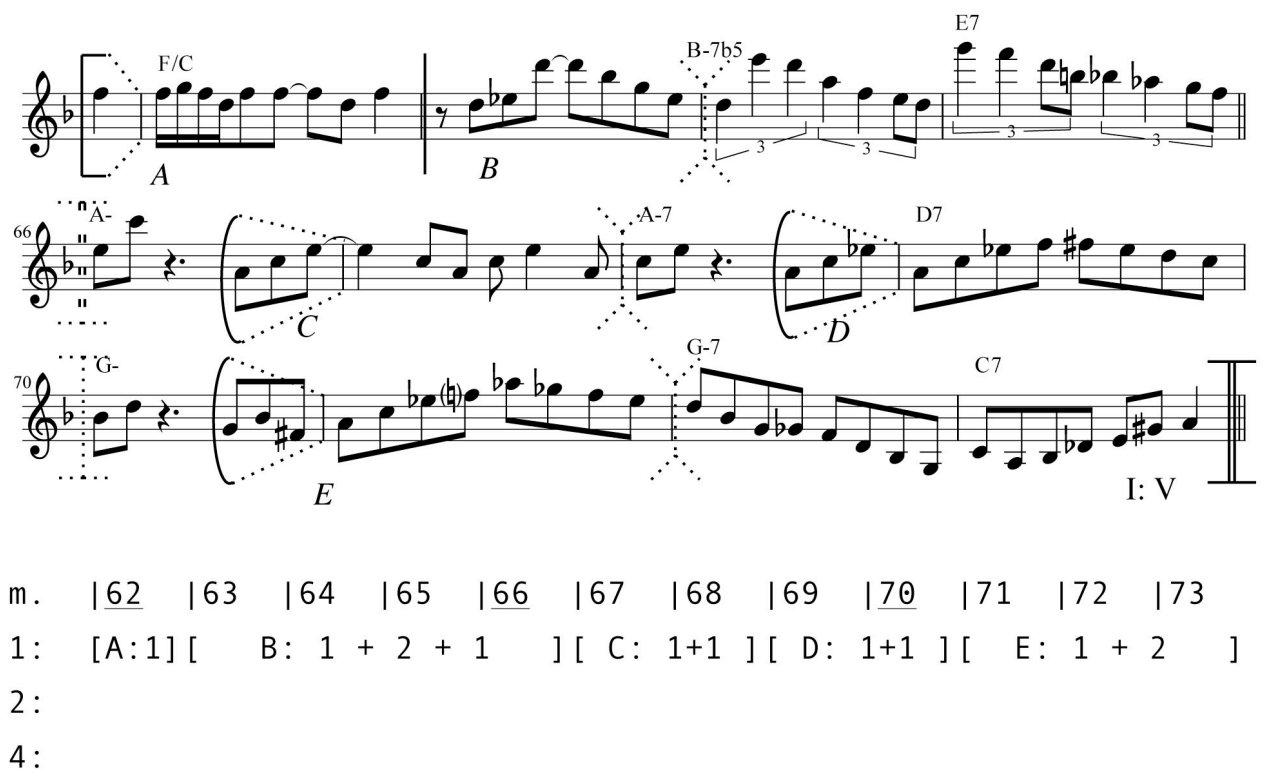

Where analysis 1 interpreted the rhyming endings as end-accentuation, analysis 2 interprets each as the " +1 " portion of a combined phrase: a gesture of initiation rather than an ending. The essential difference lies in hearing the end of segment $B$ as the beginning of the next melodic gesture (and 4-phrase), rather than as a point of closure. On this view, segment $B$ is a $1+2+1$ phrase. The rest of the analysis flows from this initial difference. Segment $\mathrm{C}$ is a $1+1$ phrase: it answers the last portion of segment $B$ and it initiates the next 2phrase; segment $\mathrm{D}$ is constructed in identical fashion, filling the rest of the four-bar hypermeasure and then initiating the next 4-phrase (m. 70). There are no phrases above the 1-phrase level in the entire passage, as each segment overlaps either a two-measure or four-measure division. Even segment $\mathrm{E}$ is a combined phrase, $1+2$, answering the " +1 " of segment $\mathrm{D}$ and filling in the rest of the hypermeasure. The result is highly dissonant, much more so than analysis 1 . This analysis does not place any strong divisions between the rhyming endings, an improvement over analysis 1 . Ultimately, I prefer analysis 2 , as I think it better reflects the fortspinnung character of the passage; I expect different listeners will have different views.

The ambiguity of this passage arises from Evans's threefold repetition of a rhyme at two-measure intervals. Given a duple metrical structure, typical of jazz, it is difficult to group a set of three regularly spaced events within the same metrical time-span. The situation is even more complex when one also 
accounts for the beginning-rhyme between segments $\mathrm{C}, \mathrm{D}$, and $\mathrm{E}$, overlapping the end-rhymes between B, C, and D. Evans's brilliant layering of these rhymes leads to a passage of extraordinary complexity. This is not an isolated example: I have observed odd-numbered rhymes and motivic repetitions in other passages by Evans, with similar effect.

\section{CONCLUSION}

I believe that a skilled listener can experience phrase rhythm, as I describe it here, in real time. The analysis of any particular segment depends only on the immediate metrical and melodic context, which should be within a listener's working memory (Berz 1995, 354). The analytical notation I employ is designed to depict a particular way of hearing, not make any "true" claims about the music. It is deliberately distinct from a pitch- or harmony-based approach to the phrase. I offer it not as a rival, but as an alternative, that may be especially suited to the peculiarities of jazz performance. Ultimately, I hope this approach will be assessed on its flexibility and its intimacy to the listening experience. I make no claim of comprehensiveness in the above analyses: I have ignored many interesting aspects of these excerpts in order to focus on phrase rhythm and explicate my methods.

I have focused on short examples rather than complete solos. At the level of entire solos, two additional features come into play. First, particular themes sometimes imply particular chorus-level phrase structures. Soloists can reinforce or revise these structures. Parker's treatment of the central formal juncture in "Ornithology," mentioned above, is one example of this. Second, in a multi-chorus solo, phrase rhythm is a powerful means by which soloists can project long-range form across a set of choruses. Frequently, the first choruses of a solo affirm the structure of the theme while later choruses depart from it. The highest-level formal division within any multi-chorus solo is the juncture between choruses. A soloist may treat this division in exactly the same way as lower-level divisions: agreement, distortion (through anacrusis or extension), or suppression. Suppressing a chorus-level division is an especially powerful tension-building device, and musicians deploy it carefully.

In the future, I foresee several avenues to develop and apply this approach. One could incorporate harmony and voice-leading more explicitly into the phrase taxonomy. While these features play an implicit role in some analytical decisions, one could refine the phrase taxonomy by considering whether phrases project a single harmony or a harmonic progression, or whether a middleground linear progression crosses multiple phrases. In terms of applications, one could apply the theory to numerous solos by a particular 
musician, or solos within a particular style, or those based on a particular theme, in order to describe characteristic phrase rhythm in that corpus.

In the hands of a skilled improviser, phrase rhythm contributes a great deal to jazz's interest and beauty. I hope that this paper increases our sensitivity to this aspect of jazz and inspires further research.

\section{WORKS CITED}

Aebersold, Jamey. 1978. Charlie Parker Omnibook. Atlantic Music Corp.

Berliner, Paul F. 1994. Thinking in Jazz: The Infinite Art of Improvisation. Chicago: University of Chicago Press.

Berz, William L. 1995. "Working Memory in Music: A Theoretical Model." Music Perception 12.3: 353-364.

Braunschweig, Karl. 2004/2005. "Rhetorical Types of Phrase Expansion in the Music of J.S. Bach.” Intégral 18/19: 71-111.

Caplin, William. 2000. Classical Form: A Theory of Formal Functions for the Instrumental Music of Haydn, Mozart, and Beethoven. New York: Oxford University Press.

Cone, Edward T. 1968. Musical Form and Musical Performance. New York: W. W. Norton and Company, Inc.

Cooper, Grosvenor and Leonard Meyer. 1960. The Rhythmic Structure of Music. Chicago: University of Chicago Press.

Dobbins, Bill. n.d. Bill Evans on Riverside. Unpublished collection of transcriptions. Personal copy.

Downs, Clive. 2000/2001. "Metric Displacement in the Improvisation of Charlie Christian." Annual Review of Jazz Studies 11: 39-68.

Forte, Allen. 1995. The American Popular Ballad of the Golden Era 1924-1950. New York: Oxford University Press.

Hanninen, Dora. 2001. "Orientations, Criteria, Segments: A General Theory of Segmentation for Musical Analysis." Journal of Music Theory 45/2: 345433.

Hasty, Christopher. 1997. Meter As Rhythm. New York: Oxford University Press.

Johnson-Laird, P.N. 2002. "How Jazz Musicians Improvise.” Music Perception 19.3: 415-442.

Koch, Heinrich Christoph. 1983. Introductory Essay on Composition, translated by Nancy Baker. New Haven: Yale University Press.

Komar, Arthur J. 1971. Theory of Suspensions. Princeton, NJ: Princeton University Press. 
Larson, Steve. 1993. "Dave McKenna's Performance of 'Have You Met Miss Jones?" American Music 11/3: 283-315.

- 1996. "The Art of Charlie Parker's Rhetoric." Annual Review of Jazz Studies 8: 141-166.

- 1998. "Schenkerian Analysis of Modern Jazz: Questions About Method." Music Theory Spectrum 20.2: 209-241.

_ 1999. "Swing and Motive in Three Performances by Oscar Peterson." Journal of Music Theory 43/2: 283-314.

- 2005. "Composition Versus Improvisation?" Journal of Music Theory 49.2: 241-75.

— Keith Waters, Steven Strunk, and Henry Martin. 2009. "Circular Thinking: A Roundtable on 'Blue in Green' and 'Nefertiti." Paper presented at the Society for Music Theory Annual Meeting, Montreal.

Lerdahl, Fred, and Ray Jackendoff. 1983. A Generative Theory of Tonal Music. Cambridge, MA: MIT Press.

Lester, Joel. 1986. The Rhythms of Tonal Music. Carbondale, IL: Southern Illinois University Press.

London, Justin. 2004. Hearing in Time: Psychological Aspects of Musical Meter. New York: Oxford University Press.

Love, Stefan. 2011. On Phrase Rhythm in Jazz. PhD diss., University of Rochester.

Mankowski, Forrest "Woody," transcriber. 2008. Best of Sonny Rollins. Milwaukee: Hal Leonard.

Martin, Henry. 1996. Charlie Parker and Thematic Improvisation. Lanham, MD: The Scarecrow Press.

Mirka, Danuta. 2009. Metric Manipulations in Haydn and Mozart. New York: Oxford University Press.

Narmour, Eugene. 1990. The Analysis and Cognition of Basic Melodic Structures: The Implication-Realization Model. Chicago: University of Chicago Press.

- 1992. The Analysis and Cognition of Melodic Complexity: The Implication-Realization Model. Chicago: University of Chicago Press.

Owens, Thomas. 1974. "Charlie Parker: Techniques of Improvisation." PhD diss., University of California Los Angeles.

Rothstein, William. 1989. Phrase Rhythm in Tonal Music. New York: Schirmer Books.

Schachter, Carl. 1980. "Rhythm and Linear Analysis: Durational Reduction." The Music Forum V: 197-232.

- 1987. "Rhythm and Linear Analysis: Aspects of Meter." The Music Forum VI: 1-60. 
Spevak, Christian; Thom Belinda; Karin Höthker. 2002. "Evaluating Melodic Segmentation." Proceedings of the II International Conference on Music and Artificial Intelligence (ICMAI): 168-182.

Strunk, Steven, 1979, "The Harmony of Early Bop: A Layered Approach." Journal of Jazz Studies 6, no. 1: 12-13.

Temperley, David. 2001. The Cognition of Basic Musical Structures. Cambridge, MA: MIT Press.

- 2003. "End-Accented Phrases: An Analytical Exploration." Journal of Music Theory 47: 125-154.

—. 2008. "Hypermetrical Transitions." Music Theory Spectrum 30: 305325.

Terefenko, Dariusz. 2004. "Keith Jarrett's Transformation of Standard Tunes." $\mathrm{PhD}$ diss. University of Rochester.

—. 2009. "Jazz Transformations of the ii7-V7-I Progression." Current Research in Jazz 1.

Waters, Keith. 1996. "Blurring the Barline: Metric Displacement in the Piano Solos of Herbie Hancock." Annual Review of Jazz Studies 8: 19-37.

Yeston, Maury Alan. 1974. The Stratification of Musical Rhythm. PhD diss., Yale University.

\section{RECORDINGS AND TRANSCRIPTIONS}

Evans, Bill. 1959. Portrait in Jazz. Riverside RLP 12-315.

"Witchcraft," by Cy Coleman. In Dobbins.

- 1961. Explorations. Riverside RLP 351.

"How Deep Is the Ocean?" by Irving Berlin. In Dobbins.

. 1961. Sunday at the Village Vanguard. Riverside RLP 376.

"Solar," by Miles Davis. In Dobbins.

Parker, Charlie. Charlie Parker on Dial, Vol. 1. Spotlite (E) SPJ 101.

"Ornithology," by Charlie Parker. In Aebersold 1978.

—. 1947. Charlie Parker on Dial, Vol. 4. Spotlite (E) SPJ 104.

"Dewey Square," by Charlie Parker. In Aebersold 1978.

. 1952. Now's the Time. Verve MGV 8005.

"Cosmic Rays," by Charlie Parker. In Aebersold 1978.

Rollins, Sonny (under Miles Davis). 1954. Bags' Groove. Prestige PRLP 7109.

"Airegin," by Sonny Rollins. In Mankowski 2008.

. 1956. Saxophone Colossus. Prestige PRLP 7079.

"Moritat," by Kurt Weill. Author's transcription. 


\section{ABOUT THE CONTRIBUTOR}

STEFAN CARIS LOVE is a Lecturer in Music at the University of Chicago. He has also taught at Oberlin Conservatory and the Eastman School of Music, where he earned his Ph.D. in Music Theory. A jazz pianist, his research focuses on bebop improvisation, meter, and form. His writing has appeared or will soon appear in the Journal of Music Theory Pedagogy, Music Theory Online, and Music Theory Spectrum. 